\title{
Effect of Various Intensities of Circuit Resistance Training on Plasma Levels of High-Density Lipoprotein-Associated Apolipoprotein O, Total Cholesterol and Triglyceride in Untrained Men
}

\author{
Abbass Ghanbari- Niaki (PhD) \\ Exercise Biochemistry Division, \\ Faculty of Sport Sciences, University \\ of Mazandaran, Babolsar, Mazandaran, \\ Iran \\ Abolfazle Aghababaeian (PhD \\ Candidate) \\ Department of Exercise Biochemistry \\ Division, Faculty of Sports Sciences, \\ University of Mazandaran, Babolsar, \\ Iran and Laboratory Sciences Research \\ Center, Golestan University of Medical \\ Sciences \\ Hamidreza Joshaghani (PhD) \\ Laboratory Sciences Research Center, \\ Golestan University of Medical \\ Sciences, Gorgan, Iran \\ Mohammad Ali Vakili (PhD) \\ Golestan University of Medical \\ Sciences, Gorgan, Iran \\ Mehran Hoseini (PhD) \\ Golestan University of Medical \\ Sciences, Gorgan, Iran \\ Corresponding author: Abolfazle \\ Aghababaeian \\ Email: aghababaeian@goums.ac.ir \\ Tel: +98-9112756248 \\ Address: Golestan University of \\ Medical Sciences and University of \\ Mazandaran, Shahid Zolfaghari \\ Boulevard. Babolsar. Mazandaran. Iran \\ Received: 01 Dec 2018 \\ Revised: 02 Jan 2019 \\ Accepted: 18 Jan 2019 \\ (c) (i) \&
}

This work is licensed under a Creative Commons Attribution 4.0 License.

\begin{abstract}
Background and Objectives: Apolipoprotein 0 (apo0) is a 198 amino acids protein that exists predominantly in high-density lipoprotein (HDL). It may exert cardioprotective effects via decreasing fat accumulation and increasing removal of cholesterol from macrophages. Although the health benefits of exercise are well documented, no study has yet investigated the effects of various types of training, including resistance training on apo0 level. Therefore, we aimed to determine effects of five weeks of circuit resistance training with different intensities on plasma levels of apo0, HDL, total cholesterol (TC) and triglyceride ( $\mathrm{TG}$ ) in young untrained men.

Methods: Forty-five age- and weight-matched healthy untrained men were randomly assigned to a control group $(\mathrm{n}=10)$ and four training groups: training at $20 \%$ intensity $(\mathrm{n}=9)$, training at $40 \%$ intensity $(\mathrm{n}=8)$, training at $60 \%$ intensity $(\mathrm{n}=7)$ and training at $80 \%$ intensity $(\mathrm{n}=0)$. The subjects performed circuit resistance training at 10 stations (30 seconds at each station) with three repetitions, without rest between stations and with 3-minute active rest between the repetitions. The training was carried out for 45 minutes per session, three sessions a week, for five weeks. Venous blood samples were taken 48 hours before the first exercise session and 48 hours after the last training session. Plasma levels of apo0, HDL, TC and TG were measured using commercial kits. Data were analyzed using repeated measures ANOVA and Tukey's post hoc test at significance level of 0.05 .

Results: After the training intervention, mean plasma level of TC and TG did not differ significantly between the study groups ( $\mathrm{P}>0.05$ ). Training at $00 \%$ of one-repetition maximum (1RM) caused a slight decrease in the apo0 concentrations. Moreover, apo0 concentration was significantly higher in the $20 \%$ IRM training group compared to other study groups $(\mathrm{F}=11.599, \mathrm{P}<0.002)$.

Conclusion: 0ur results indicate that circuit resistance training at $80 \%$ of $1 \mathrm{RM}$ can decrease HILL-associated apo0 level but does not significantly alter other parameters.

KEYWORDS: Circuit resistance training, HDL-0, TC, TG, Young men.
\end{abstract}

This paper should be cited as: Ghanbari- Niaki A, Aghababaeian A, Joshaghani HR, Vakili MA, Hoseini M[Effect of Various Intensities of Circuit Resistance Training on Plasma Levels of High-Density Lipoprotein-Associated Apolipoprotein O, Total Cholesterol and Triglyceride in Untrained Men]. mljgoums. 2019; 13(4):23-28 


\section{INTRODUCTION}

Coronary artery disease is one of the leading causes of death in both developed and developing countries. Increased levels of total cholesterol (TC), low-density lipoprotein (LDL) and triglyceride (TG) as well as lowered amount of high-density lipoproteincholesterol (HDL-C) are strong independent markers for coronary artery disease.

Studies have shown that resistance training can change protein components of lipoproteins, such as apolipoprotein $\mathrm{O}$ (apoO). ApoO is mainly found in HDL but can be also present in LDL and VLDL in low amounts. This apolipoprotein can exert cardioprotective effects by decreasing fat accumulation and increasing the removal of cholesterol from macrophage cells (1).

Alteration of lipids and apoO levels are considered risk factors of cardiovascular disease. Minor structural or functional alteration of apoO can cause major problems in metabolism of lipids (2).

Regular physical activity is one of the best ways to improve lifestyle and reduce risk of cardiovascular disease $(3,4)$. The effects of physical activity on lipid and lipoprotein levels are well-established (5). Resistance training increases muscle strength, muscle mass, free fatty acids metabolism and energy expenditure. Therefore, it can be effective in improving the metabolic risk factors associated with cardiovascular disease (6). Previous studies indicated that resistance training could lower hepatic and circulating lipid levels (7). In ovariectomized rats, 12 weeks of resistance training decreased liver and muscle lipid levels and improved blood lipid profiles (8). In addition, eight weeks of resistance training improved lipid profiles in rats with a normal or high-fat diet (9). Despite these findings, there is little known about the effects of resistance training on apoO and HDL levels. Therefore, we aimed to investigate effects of five weeks of resistance training on levels of apoO, HDL-C, TC and TG in untrained young men.

\section{MATERIALS AND METHODS}

In this quasi-experimental study, 45 non-active male medical students (average age: $19.52 \pm 0.96$ years, average weight: 16.40 $\pm 78.52 \mathrm{Kg}$ ) from the Golestan University of Medical Sciences (Gorgan, Iran) were enrolled. Prior to participation, all procedures and research objectives were explained to the subjects and written consent was obtained. Inclusion criteria included lack of regular exercise for at least six months and no history of chronic diseases (liver, diabetes, kidney and cardiovascular disease), no history of drug/alcohol addiction and lack of physical disability. After homogenization based on individual characteristics, especially total strength, the subjects were randomly assigned to five groups of control $(\mathrm{n}=10)$, training at $20 \%$ intensity $(\mathrm{n}=9)$, training at $40 \%$ intensity $(\mathrm{n}=8)$, training at $60 \%$ intensity $(\mathrm{n}=7)$ and training at $80 \%$ intensity $(n=8)$ (Table 1$)$.

Table 1- Characteristics of the subjects in each study group

\begin{tabular}{|c|c|c|c|c|c|}
\hline \multirow[t]{2}{*}{ Group } & Control $(n=10)$ & $\begin{array}{c}\text { Training at } 20 \% \\
\text { intensity }(\mathbf{n}=9)\end{array}$ & $\begin{array}{c}\text { Training at } 40 \% \\
\text { intensity }(n=8)\end{array}$ & $\begin{array}{c}\text { Training at } 60 \% \\
\text { intensity }(n=7)\end{array}$ & $\begin{array}{c}\text { Training at } 80 \% \\
\text { intensity }(\mathrm{n}=8)\end{array}$ \\
\hline & $\begin{array}{l}\text { Mean } \pm \text { standard } \\
\text { error }\end{array}$ & $\begin{array}{l}\text { Mean } \pm \text { standard } \\
\text { error }\end{array}$ & $\begin{array}{l}\text { Mean } \pm \text { standard } \\
\text { error }\end{array}$ & $\begin{array}{l}\text { Mean } \pm \text { standard } \\
\text { error }\end{array}$ & $\begin{array}{c}\text { Mean } \pm \text { standard } \\
\text { error }\end{array}$ \\
\hline \multicolumn{6}{|l|}{ Variable } \\
\hline Age (years) & $20 \pm 1$ & $19 \pm 1$ & $19 \pm 1$ & $19 \pm 1$ & $18 \pm 1$ \\
\hline Height $(\mathbf{C m})$ & $177 \pm 8$ & $178 \pm 3$ & $176 \pm 6$ & $183 \pm 7$ & $181 \pm 4$ \\
\hline Weight (Kg) & $76 \pm 17$ & $77 \pm 20$ & $76 \pm 16$ & $81 \pm 13$ & $81 \pm 15$ \\
\hline BMI $\left(\mathrm{Kg} / \mathbf{m}^{2}\right)$ & $24 \pm 4$ & $24 \pm 6$ & $24 \pm 3$ & $24 \pm 2$ & $24 \pm 5$ \\
\hline $\begin{array}{l}\text { Back extensions } \\
\quad(\mathrm{Kg})\end{array}$ & $24 \pm 5$ & $21 \pm 5$ & $18 \pm 6$ & $18 \pm 10$ & $18 \pm 8$ \\
\hline Abdomen (Kg) & $28 \pm 6$ & $22 \pm 8$ & $25 \pm 6$ & $24 \pm 7$ & $21 \pm \mathbf{1 0}$ \\
\hline Back arm (Kg) & $42 \pm 7$ & $31 \pm 5$ & $37 \pm 7$ & $44 \pm 15$ & $35 \pm 6$ \\
\hline $\begin{array}{l}\text { Barbell Bench } \\
\text { Press (Kg) }\end{array}$ & $30 \pm 6$ & $26 \pm 11$ & $28 \pm 10$ & $33 \pm 11$ & $24 \pm 10$ \\
\hline leg Squat (Kg) & $57 \pm 11$ & $54 \pm 15$ & $53 \pm 12$ & $64 \pm 14$ & $54 \pm 11$ \\
\hline Leg (Kg) & $95 \pm 35$ & $145 \pm 209$ & $61 \pm 14$ & $63 \pm 12$ & $61 \pm 11$ \\
\hline Front arm (Kg) & $16 \pm 3$ & $13 \pm 5$ & $11 \pm 5$ & $14 \pm 6$ & $11 \pm 6$ \\
\hline Back foot (Kg) & $21 \pm 2$ & $23 \pm 9$ & $16 \pm 5$ & $19 \pm 2$ & $18 \pm 5$ \\
\hline Front leg (Kg) & $34 \pm 7$ & $36 \pm 12$ & $31 \pm 12$ & $38 \pm 4$ & $35 \pm 10$ \\
\hline Arm pit (Kg) & $49 \pm 6$ & $47 \pm 8$ & $44 \pm 5$ & $48 \pm 6$ & $44 \pm 6$ \\
\hline
\end{tabular}


Our training protocol was based on a protocol designed by Abbas Ghanbari and Abolfazl Aghababaiyan (10). The subjects first became familiar with the training environment and equipment. Value of one-repetition maximum (1RM) of the intended movements (bench press, seated cable row, arm cable curl, triceps cable curl, lying leg curl, barbell squat, lumbar extension, abdominal, decline sit-up, quadriceps) was calculated using the following formula and through trial and error: $\mathbf{1 r m}=\frac{{ }_{\mathbf{9 5}}-(\text { repid }) \times \mathbf{2 5} \%}{\mathbf{0}}$.

After warm up, the subjects performed the movements in 10 stations at different intensities (20,40, 60 and $80 \%)$ of 1RM for 30 seconds without rest between the stations. The trainings were performed at medium speed and finished with cool down. The exercises were performed in three sets with 3-minute active rest between each set. The heart rate of the subjects was assessed within 6 seconds immediately after completing each set. Fasting blood samples $(10 \mathrm{cc})$ were taken 48 hours before the first training session and 48 hours after the last training session in sitting position. The samples were collected in EDTA-coated tubes. After centrifugation at $1500 \mathrm{~g}$ for 15 minutes, supernatant was transferred to a separate tube and kept at -70
${ }^{\circ} \mathrm{C}$. ApoO level was measured using commercial ELISA kits. HDL-C was measured by photometric method (Pars Test, Tehran, Iran) with coefficient of variation and sensitivity of $0.81 \%$ and $1 \mathrm{mg} / \mathrm{ml}$. Level of TC and TG was determined by enzymatic (CHOD-PAP) calorimetric method (Pars Test Tehran, Iran), respectively. Coefficient of variation and sensitivity of the method was $61 \%$ and $5 \mathrm{mg} / \mathrm{ml}$ for TC and $1.04 \%$ and 5 $\mathrm{mg} / \mathrm{ml}$ for TG, respectively. All mentioned factors were measured using the Prestige 24i chemistry analyzer (Japan).

Normality of data was assessed using the Kolmogorov-Smirnov test. Data analysis was performed with SPSS 16 using one-way ANOVA, two-way repeated measures ANOVA Tukey's test at significance of 0.05 .

\section{RESULTS}

The five-week training program at all intensities caused a significant increase in HDL-associated apoO level. Although plasma apoO increased in all training groups, this increase was statistically significant only in the $20 \%$ 1RM group $(\mathrm{F}=11.599, \quad \mathrm{P}<0.002$, Figure.1). The training at various intensities caused no significant change in the plasma concentrations of TC and TG (Figures 2 and $3)$.

Figure 1- Mean plasma concentration of apoO in different groups after five weeks of circuit resistance training

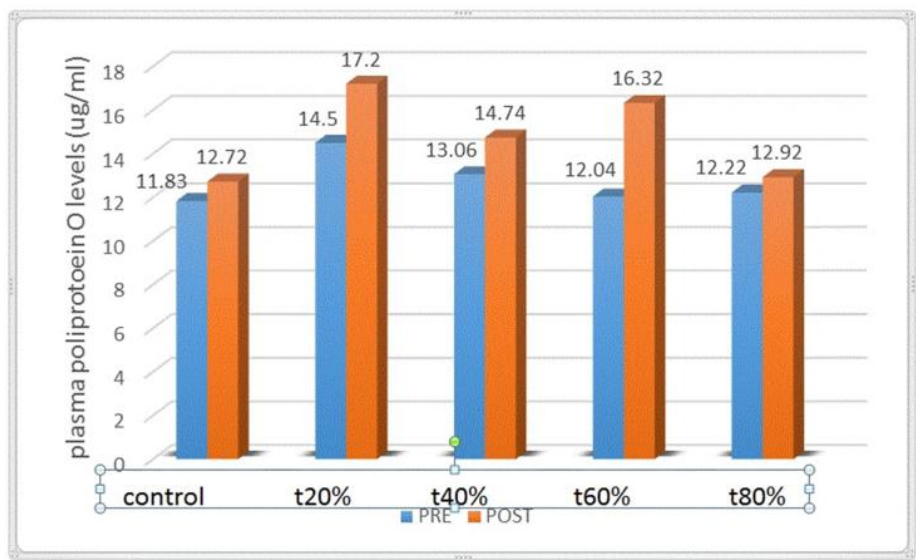


Figure 2- Mean plasma concentrations of TC in different groups after five weeks of circuit resistance training

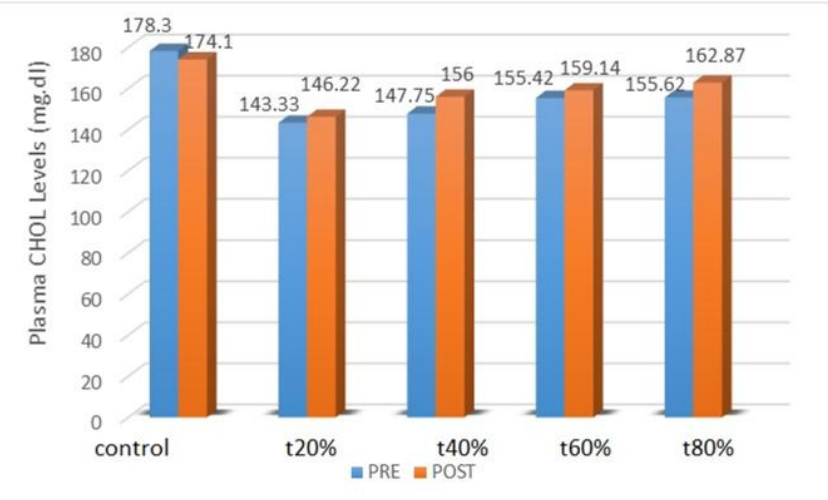

Figure 3- Mean plasma concentration of TG in different groups after five weeks of circuit resistance training

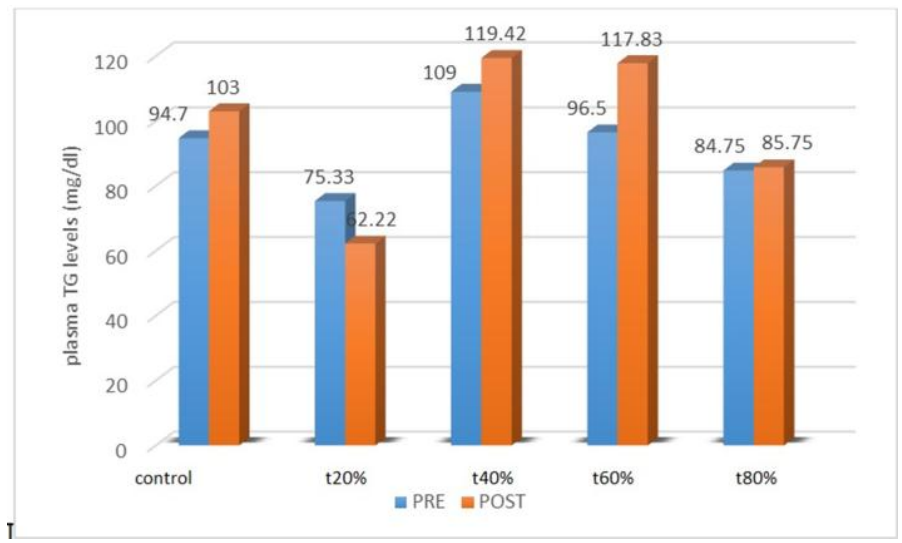

\section{DISCUSSION}

The results of this study showed that performing five weeks of circuit resistance training at different intensities can affect some of the cardiovascular risk factors (11). Although much research has been done on the impact of endurance and strength training on lipoprotein and lipid levels (12-14), there is little known about the effects of circuit resistance training on apoO and plasma lipid profile. In this study, the five-week resistance training protocol caused a significant increase in apoO level in all training groups but did not significantly alter other tested parameters. There was no significant difference in plasma TC levels between the study groups. This finding is in line with findings of Turkman et al. (15) and Yektayar et al. (16).

Plasma TG levels did not differ significantly between the study groups, which were consistent with some studies $(17,18)$ but contrary to the results of some other studies $(19,20)$. Exercise increases lipoprotein lipase (LPL) and decreases hepatic lipase (HL) activity. Considering that the increased activity of LPL increases catabolism of TG-rich lipoproteins, it is expected to observe TG rise after physical activity (21). In addition, regular exercise can inhibit HL activity (22), which could decrease the TG content of VLDL and LDL.

Enzymes such as LPL, hepatic TG lipase and cholesteryl ester transfer protein play an important role in alteration of HDL concentrations. Plasma LPL changes lipoprotein concentration through hydrolysis of TG. However, increased lipoprotein levels immediately after exercise is not due to LPL activity but possibly related to a decrease in the concentration of cholesteryl ester transfer proteins, which are responsible for carrying fats in HDL molecules and other lipoproteins. This in turn slows down lipoprotein catabolism (half-life) and ultimately increases lipoprotein concentrations (23). Given that adipose tissues are supplied with capillaries and innervated by sympathetic nerve fibers, which can regulate 
lipid metabolism, one cannot consider a single mechanism responsible for alteration of lipid parameters. Another important cause of lipolysis is stimulation of beta-adrenergic receptors in adipose tissue. Increased sympathetic nervous system activity and immediate release of both epinephrine and norepinephrine after exercise lead to lipolysis (24). In a previous study (unpublished), we investigated effects of four weeks of circuit resistance training and supplementation with milk, whey cheese and protein whey on plasma HDL-apoO levels in high school students. The results showed that apoO level decreased significantly at the end of the study in all groups except for the milk supplementation group. However, apoO level did not differ significantly between the study groups (25).

Similar to apolipoprotein $\mathrm{B}$, apoO secretion has a microsomal triglyceride transfer protein (MTP)-dependent mechanism. In fact, apoO is secreted in VLDL and then transferred to HDL. Moreover, apoO expression is significantly associated with MTP expression (1). It has been reported that patients with acute coronary syndrome has twice as high apoO level than healthy individuals (26). The decrease in HDL-apoO level could be attributed to a possible down-regulation effect

\section{REFERENCES}

1. Lamant M, Smih F, Harmancey R, Philip-Couderc P, Pathak A, Roncalli J, et al. ApoO, a Novel Apolipoprotein, Is an Original Glycoprotein Upregulated by Diabetes in Human Heart. J Biol Chem. 2006; 281(47): 36289-302.

2. Mohaddesa Mahdian. Effect of 4 weeks of circular strength training with and without supplementation of milk, protein, lor on apolipoprotein O levels, total HDL, growth hormone and plasma insulin in untrained young men. master thesis. 2013.

3. Braith RW, Stewart KJ. Resistance exercise training: Its role in the prevention of cardiovascular disease. Circulation. 2006; 113(22): 2642-50.

4. Khabazian BM, Ghanbari-Niaki A, SafarzadehGolpordesari A, Ebrahimi M, Rahbarizadeh F, Abednazari H. Endurance training enhances ABCAl expression in rat small intestine. Eur J Appl Physiol. 2009; 107(3): 351-8.

5. Pitsavos C, Panagiotakos DB, Tambalis KD, Chrysohoou C, Sidossis LS, Skoumas J, et al. Resistance exercise plus to aerobic activities is associated with better lipids' profile among healthy individuals: the ATTICA study. QJM. 2009; 102(9): 609-16. doi: 10.1093/qjmed/hcp083. on MTP expression in the liver since a study has shown that resistance training (treadmill running) decreases MTP mRNA levels in ovariectomized or non-ovariectomized rats treated with estradiol $(27,28)$. The decrease in HDL-apoO level observed in our subjects might be due to hepatic TG-rich VLDL secretion. Given that administration of sex hormones can affect apoO level (25) and the increase in apoO level was relatively higher in the training groups than in the control group, it can be inferred that training-induced changes in the sex hormones may have contributed to the apoO alteration. Considering the lack of enough studies in this regard, it is not yet possible to propose an exact mechanism for the decreased HDL-apoO level following resistance training. Nevertheless, the effects observed in the training groups could also reflect the relative cardioprotective effects of the training protocol used in the present study.

\section{CONCLUSION}

Our results indicate that resistance training may reduce risk of developing cardiovascular disease.

\section{CONFLICT OF INTEREST}

The authors declare that there is no conflict of interest.

6. Marques E, Carvalho J, Soares JMC, Marques F, Mota $\mathrm{J}$. Effects of resistance and multicomponent exercise on lipid profiles of older women. Maturitas. 2009; 63(1): 848. doi: 10.1016/j.maturitas.2009.03.003.

7. Zelber-Sagi S, Nitzan-Kaluski D, Goldsmith R, Webb M, Zvibel I, Goldiner I, et al. Role of leisure-time physical activity in non alcoholic fatty liver disease: a population-based study. Hepatology. 2008; 48(6): 17918. doi: 10.1002/hep.22525.

8. Leite RD, Prestes J, Bernardes CF, Shiguemoto GE, Pereira GB, Duarte JO, et al. Effects of ovariectomy and resistance training on lipid content in skeletal muscle, liver, and heart; fat depots; and lipid profile. Appl Physiol Nutr Metab. 2009; 34(6): 1079-86. doi: 10.1139/H09-116.

9. Speretta GF, Rosante MC, Duarte FO, Leite RD, Lino $\mathrm{AD}$, Andre RA, et al. The effects of exercise modalities on adiposity in obese rats. Clinics. 2012; 67(12):14691477.

10. Aghababaeian A. Effects of aerobic exercise at different intensities on cardiovascular risk factors in men, according to the enzyme myeloperoxidase, lipoproteins, apolipoproteins $M$ and $O$ in $H D L$ and plasma.(2019 thesis PHD) 
11. Ghanbari-Niaki A, Ali Akbari Bidokhti M, Saeedi A, Ardeshiri S, Naghizadeh Qomi M. Effect of short-term resistance training with and without plant propagation of saffron on fat and lipid concentration Plasma Lipoprotein in Young College Students. Applied Sports Physiolysis Research Report. 2014; 12: 24.

12. Vincent, K, Braith, R, Bottiglieri, T, Vincent, H, Lowenthal, D. Homocysteine and lipoprotein levels following resistance training in older adults. Preventive Cardiology. 2003; 6(4): 197-203.

13. Ghanbari-Niaki A. Treadmill Exercise Training Enhances ATP Binding Cassette protein-A1 (ABCA1) Expression in Male Rats' Heart and Gastrocnemius Muscles. Endocrinology \& Metabolism. 2010; 8(4): 206210.

14. Ghanbari-Niaki A, Khabazian B, Hossaini-Kakhak A, Rahbarizadeh F, Hedayati M. Treadmill Exercise Enhances ABCAl Expression in Rat Liver. Biochem Biophys Res Commun. 2007; 361(4): 841-6.

15. Roghani T, Torkaman G, Movasseghe S, Hedayati M, Goosheh B, Bayat N. The Effect of 6-Week Submaximal Training With and Without External Loading on Cardiovascular Fitness, Balance, Cortisol, and Lipid Profiles in Osteoporotic Postmenopausal Women. Iranian Journal of Endocrinology and Metabolism. 2012; 13(6): 587-597.

16. Yektayar M, Mohammadi S, Ahmadi Deharshid K, Khodamoradpour M. Comparison of the effects of resistance, endurance and combined exercises on lipid profile of non-athlete healthy middle aged men. SJKU. 2012; 16(4): 26-36.

17. Safarzade A, Rohi H, Fathi R, Talebi-Garakani E. Effect of progressive resistance training on serum amyloid A and apolipoprotein A-I levels in diabetic Rats. koomesh. 2013; 15(1): 22-30.(Persian)

18. Pleasant Ronique, N, Villarreal M, Wooten JS, Hein RM, Menzies RD, Phillips MD. Responses of Lipids And Lipoproteins Following Acute And Training Resistance Exercise In Obese Postmenopausal Women. Medicine \& Science in Sports \& Exercise. 2009: 2(1): 4. DOI: 10.1249/01.MSS.0000356036.92619.45.

19. Behall, KM, Howe, JC, Martel, G, Scott, WH, Dooly, CR, (2003). Comparison of resistive to aerobic exercise training on cardiovascular risk factors of sedentary,overweight premenopausal and postmenopausal women. Nutrition Research. 23(5): 607619.
20. Sung R, Chang S, Mo S, Woo K, Lam C. Effects of dietary intervention and strength training on blood lipid level in obese children. Arch Dis Child. 2002; 86(6): 407-410. doi: 10.1136/adc.86.6.407.

21. Askari A, Askari B, Fallah Z, Kazemi Sh. Effect of eight weeks aerobic training on serum lipid and lipoprotein levels in women. J Gorgan Uni Med Sci. 2012; 14(1): 26-32. (Persian)

22. Pronk NP, Crouse SF, O'Brien BC, Rohack JJ. Acute effects of walking on serum lipids and lipoproteins in women. J Sports Med Phys Fitness. 1995; 35(1): 50-8.

23. Amouzad Mahdirejei H, Aghababaeian A, Mirsaiedii M, Fadaei Reyhan Abadei S, Abbaspour Seyedii A. Effect of 8 weeks of resistance training on hemostasis indeces and lipid profile in adult men.J Gorgan Uni Med Sci. 2014; 16(2): 21-28. (Persian)

24. Wang JS, Chow SE. Effects of exercise training and detraining on oxidized low-density lipoproteinpotentiated platelet function in men. Arch Phys Med Rehabil. 2004; 85(9): 1531-7.

25. Ghanbari-Niaki. A and colleagues. Effect of 4 weeks of circular resistance training with and without supplementation of milk, protein, lor on apolipoprotein $O$ levels, total HDL, growth hormone and plasma insulin in untrained young men. 2012. thesis.

26. Yu Bi-lian, Wu lu Chen, Zhao Sp. Plasma apolipoprotein $O$ level increased in the patients with acute coronary syndrome. J Lipid Res. 2012; 53(9): 1952-7. doi: 10.1194/jlr.P023028.

27. Chapados NA, Seelaender M, Levy E, Lavoie JM. Effects of exercise training on hepatic microsomal triglyceride transfer protein content in rats. Horm Metab Res. 2009; 41(4): 287-93.

28. Barsalani R, Chapados NA, Lavoie JM.Hepatic $V L D L-T G$ production and MTP gene expression are decreased in ovariectomized rats: effects of exercise training. Horm Metab Res. 2010; 42(12): 860-7. doi: 10.1055/s-0030-1267173. 